\title{
A Framework for Coordination Process into Construction Projects
}

\author{
Wesam S. Alaloul ${ }^{a}$, Mohd Shahir Liew and Noor Amila BWA Zawawi \\ Department of Civil and Environmental Engineering, Universiti Teknologi PETRONAS, 32610 Seir Iskander, Perak, Malaysia
}

\begin{abstract}
Construction industry is recognized as high fragmentation, low efficiency, cost and time overruns in contrast with other industries. These peculiarities are the main roots of poor performance facing by the industry. Effective coordination is vital in construction projects success and mitigate the fragmentation dilemma, however it is often difficult to achieve and need iterative process. Coordination is core issue to improve performance in construction project. Relevant studies have addressed the coordination process importance and implementation, but not in a framework. This paper propose a framework for coordination process in construction projects, as well as its relationship with performance. The objective of the framework is to provide a roadmap for the construction parties to realize operational excellence so that collectively stakeholders can recognize the effect of coordination process application on the project performance. The data were obtained from literature review and structured interviews with five experts. The analysis produced the framework of coordination based on the extensively used procedures for information and data flow between stakeholders.
\end{abstract}

\section{Introduction}

Construction industry is the producer of infrastructures and facilities through executing a complex activity and large-scale projects. It differs from manufacturing industry in terms of involving mass production of similar items without a designated purchaser. The uniqueness and the fragmented status of construction projects have been significantly affect its performance in terms of cost, time, and quality indicators $[1,2]$.

The relationship between construction industry and economic development is well posited. Construction as a vital industry contributes from $6-10 \%$ the Gross Domestic Product (GDP) of developed countries, and 3-6\% to the GDP of developing countries [3]. However, construction projects comprises a wide range of activities including construction, upgrading, repair, and demolitions. The fragmentation status in the project life cycle hinders the teamwork focusing on the best interests of the project. For example, there is less incentive under the traditional approach for a contractor to advice on the design stage. The interaction among all participants in order to distribute the correct information on time is very critical [4]. On the other hand, the existences of significant number of wastes, which can be avoided or minimized, have depleted the overall performance of the industry. In UK construction projects, where up to $30 \%$ of construction is rework, only $40-60 \%$ of labour effectiveness, and at least $10 \%$ of materials are wasted [1, 4]. There is increasing of realization among the construction industry stakeholders of the need to enhance the efficiency of work during the construction project life cycle and sustain working environment, but the steps to achieve them is not clear.

\footnotetext{
${ }^{a}$ Corresponding author: wesamalool@hotmail.com
}

Coordination process became a strategy among parties in construction seeking to recognize operational efficiency [5]. Efficient operation can be realized by rationalization operations upright within practical professional units or straight across the entire construction project using effective coordination between management and first line of work [6]. The goal of coordination process is to decrease the information lag through synchronization and integration of activities and responsibilities to ensure that the resources are used most efficiently in pursuit of the predefined objectives.

This paper aim to develop coordination framework that could be used in enhancing the current performance status. Even the value of keeping construction stakeholders coordinated have been figured, the challenge is the implementation of coordination process iteratively. Too often, coordination process in construction projects fails because of the lack or insufficiency, i.e. quality and quantity. However, coordination quality rely on expected forms of communication procedures. Getting work to flow reliably and predictably on a construction site requires the impeccable alignment of the entire coordination process. Coordination induces all fragmentation and information flow problems to be settled among the related participants, and to be eliminated from the hierarchy. The degree of coordination process required for any project depend on its complexity and the amount of exchanged information [7].

The framework is a conceptual in nature and would display the features that should be measured to accomplish effective coordination, a framework would not only show features but would also recommend methods on how to put them into real work. A framework is appropriate for 
presenting an overall image and assembly for applying coordination advantages [8]. This exploratory study investigates coordination process to pave the way for further study of coordination application. Professionals can procedure the framework to appraise how efficiently their coordination process, realize detailed faults on coordination quality and quantity, and enhance them to rise coordination efficiency.

\section{Literature Review}

Management strategy in construction is largely taken from other industries. Probably, such as manufacturing, which is not fragmented like construction, nor it has as many closely dependent and dissimilar activities on a critical path. Work force productivity in construction industry has declined about $20 \%$ between 1964 and 2003, while other industries improved by more than $200 \%$ [2, 4]. In manufacturing industry, production, procurement and transportation is concerned with the design, analysis, and control of production units. Therefore, the coordination of operational units across supply chains is essential function. However, coordination process in construction takes a disjointed path instead of a straight one. It is critical, especially when it comes to multiple concurrent projects. Coordination is important among the same party within individual units, as well as among different parties across the entire project. It will offer the construction industry more flexibility to react to the dynamic environment [5]. The ideal production system embodied in manufacturing industry was used to develop a more overarching production management paradigm for project-based production systems as in construction industry. However, production can be conceptualized in three complementary way in construction projects as; Transformation "is the production of inputs into outputs", or Flow "is a movement that is smooth and uninterrupted from one crew to the next", and Value generation "What the customer is actually paying for the project to produce and install" [9]. Recognizing that construction sites reflect prototypical behaviour of complex and chaotic systems, especially in the flow of both material and information on/off site.

Xue, et al. [6] suggested that construction should be modelled using chaos and complex systems theory. Unlike manufacturing, construction is a project based-production process, therefore the uniqueness of individual projects causes turnover in participants from project to project. Coordination is concerned with the alignment and holistic pursuit of concurrent and continuous improvements in all dimensions of construction projects: design, construction, operation, maintenance, and demolition [8]. This study derived coordination framework to be used on construction projects based on the previous literature and interviews with experts from academic, governmental, and privet sector in construction industry.

While a shift of focus on the activity constitutes an important step forward to understand coordination process in organizations, a preoccupation with contact and communication appears to be difficult in a sustain manner. Existing 'practice-based' theorizing is tied to the assumption that coordination process occurs only when interdependent actors interact. Moreover, more considerations of coordination requires when different parties work together [10]. Coordination need to be thought as a much more inclusive process, being accomplished when emerging and enacting strategies, which aim to pull together all the requirements to execute physical tasks $[5,11]$.

Coordination can be defined as "the process of managing dependencies among activities and linking together different parts to accomplish a collective set of tasks" [12]. Essentially, the delinquent of coordination is the construct of interdependence, which affects task uncertainty and information processing capacity [11]. According to Crowston [13] interdependence is "the extent to which a task requires different departments to engage in work flow, information, and resources, where actions in one unit affect the actions and work outcomes in another unit. If the activities of two units are interdependent, the levels of uncertainty that underlie their interaction need to be explored in relation to how different parties communicate. A number of studies has yet revealed that coordination also depends on the kind, not just the amount, of information and knowledge to accomplish a particular activity, while activity interdependence does not originate only from the contingent relations among units $[6,14]$. Coordination process approach to contract aligns project objectives with the interests of key participants. However, the effective application of coordination process relies on participant selection, transparency and continuing dialog $[8,14]$. Project members coordinate their work via approaches such as meetings, plans, and joint site visits. However, coordination process on construction projects facing significant barriers. The nature of construction projects itself creates some barriers that are difficult to handle without making wholesale different from current procedures. Coordination barriers are common in interparty and between different parties of project $[2,10]$.

The complexities of construction projects require a continuous coordination among many parties with widely disparate skills and experiences. ASCE has been offered 13 criteria to improve construction project coordination: (1) clear definition of the owner's project objectives, (2) coordination procedures, (3) schedules, (4) budgets, (5) written contract clarifications, (6) progress reports, (7) joint reviews of documents, (8) distribution and review of field reports and lab tests, (9) joint visits to work sites, (10) formal compliance reporting, (11) procedures for reporting discrepancies, (12) change order procedures, and (13) coordination meetings $[14,15]$. Studies have discussed the relationship between the time spent on coordination process and the project performance. Although Hegazy, et al. [16] found that, holding one or more coordination meetings per month during the design stage reduced the cost by $35 \%$. On the other hand, Hossain [17] reported, project performance did not improve significantly beyond a certain degree of interaction. Furthermore, there was extremely less rework leading to shorter duration $[14,18]$.

It is obvious that, what has been discussed does not yet provide an integrated and complete theoretical foundation for coordination process in construction project. However, a better theoretical framework for coordination process can be proposed. 


\section{Research Methodology}

In development of coordination process framework, this research implements a review of the present literatures and procedures that have been used in the construction projects. The review does not aim to develop or argue the validity of present practices, nevertheless to categorize and assemble the present practices to generate a universal coordination factors in construction industry and other industries as well. While some of present studies has recorded a few coordination approaches, they differ in terms of area, contributors and business [8, 10, 16-18].

In this study, the first stage was a literature review, followed by data collection involving structured interviews and archiving of documentation for the second stage. The main requirements of a framework are then recognized, tailed by a clarification of how the framework was created, its core parts and its gains. Direction on applying the approaches involved in the framework were defined and the predictable results and key structures were emphasized as well. Figure 1 shows the research procedure of coordination framework impediment. A complete literature review was initially commenced to recognize and conform the list of coordination factors that cover the technique for additional search. Based on hard argument from literature review, 53 coordination factors were identified.

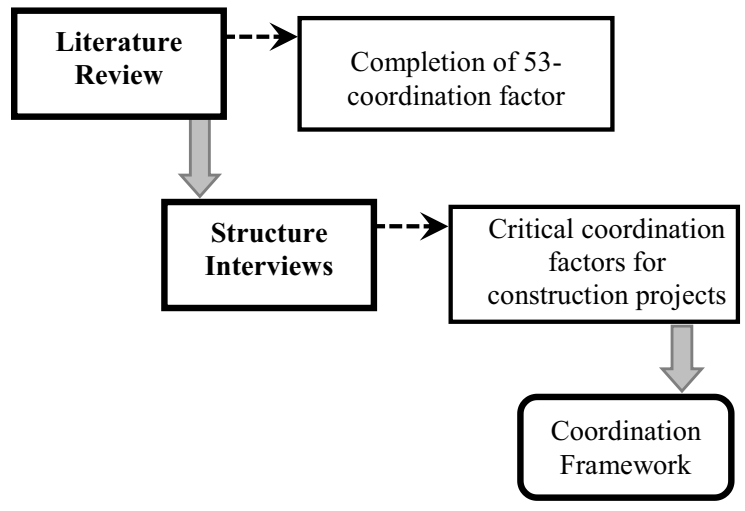

Figure 1. Compilation of coordination framework.

The interviews aimed to expurgate undesirable influences of the researcher from the conversations, by triangulation of the data with other sources in the literature. The use of the interview is transparent and qualified in terms of method $[8,18]$. To hold a better sympathetic of present practices and wonders in construction industry, five face-to-face interviews were done with skilled experts in carrying construction projects to authorize the variables created from the literature and identify the coordination factors within the background that have not been included in literature review. The description of interviewees are shown in Table 1.

The interviewees included two experts from government department, two experts from industry and another one from the academic. The selection of the participants was based on their experience in dealing with construction projects coordination. The collective of experts from various backgrounds could give balanced insight and views.
Table 1: Interviewees' profile

\begin{tabular}{|l|c|c|c|}
\hline position & Experience & Function & Sector \\
\hline $\begin{array}{l}\text { Project } \\
\text { manager }\end{array}$ & 12 & $\begin{array}{l}\text { Policy } \\
\text { maker }\end{array}$ & Governmental \\
\hline $\begin{array}{l}\text { Quantity } \\
\text { surveyor }\end{array}$ & 10 & $\begin{array}{l}\text { Policy } \\
\text { maker }\end{array}$ & Governmental \\
\hline $\begin{array}{l}\text { Project } \\
\text { manager }\end{array}$ & 14 & Contractor & Private \\
\hline Architect & 9 & Consultant & Private \\
\hline Professor & 13 & Consultant & Education \\
\hline
\end{tabular}

The list of questions was sent by email at least one day before the interview, to allow the expert to think about their responses. The interview lasted from 30 to 40 minutes for each session. The interviews have resulted in the adaptation of the list of coordination derived from the literature because of irrelevance and redundancy. The findings from the literature review and preliminary interviews are the basis to form and finalize the framework of coordination process for construction projects.

\section{Results and discussion}

Evidence from literature indicated that the current practices of construction management and the utilized approaches fail to deliver projects on time, at budget, and at desired quality. With recurring negative experiences on projects, evidenced by endemic quality difficulties and rising litigation, it became obvious that the governing principles of construction management required revisiting $[2,3]$. When executing construction projects, professionals from different backgrounds are brought together at various stages to achieve the projects objectives.

This environment increase the probability of conflicts because these professionals have a tendency to work in isolation, while making decisions that affect one another. In particular, the use of coordination concepts have been proposed to enhance the performance and sustain relationships. However, managing the interaction between activities and combined effects of interdependence is a first concern in coordination process since their interactions highly affects project performance $[1,11,17]$.

\subsection{Coordination framework components}

The motivation for creating a framework is to provide the backbones for initiation coordination process creativities in an organized method and offers direction on how to proceed if a group of objectives needs to be satisfied. Therefore, the framework can be applied to improve plans for enhancing at each phase of construction procedure and to arrange the distribution of resources and staffs in efficient manner. The framework will cover the whole project to optimize efforts focus on reliability of collective workflow; in contrast, traditional project management focuses on enhancing productivity of each activity independently. In fact, the proposed coordination framework considered as the angle stone of coordination process application, the final aim of which was to create 
an instrument that could be practical in construction projects to enhance performance and the level of satisfaction. It should satisfy two main requirement, 'expected' and 'attractive'. The first one refers to those features that answers 'what is' and 'how to' achieve efficient coordination process in construction. The second, refers to merit that may improve the framework but are not critical $[8,16]$.

The next phase in the framework creation procedure was to form a diagram that measured the entire vital and the smart requirements deliberated. As argued earlier, the request for information and number of meetings operation can be applied as displays of an organization's coordination level, but since their consciousness and apply can be reproduced in the organization coordination strategy, it was obvious to include them into the framework. On the other hands, the culture of construction parts and their sub-partners. Since various parties in the construction industry might adopt a different order to achieve complete integration and coordination that not necessary to be all consistent. The framework should take these industry dynamics and unique characteristics into consideration for widespread adoption.

In coordination process, downstream stakeholders are involved in front end planning and design through crossfunctional teams [16]. The pull techniques govern the flow of information and materials, from upstream to downstream rather than, push techniques govern the release of information and materials. Uncertainty in construction projects requires coordination of multidisciplinary professions, activities and information, which contributed to the lack of integration of design information, which leads to unnecessary time variations and design changes in the construction projects [10]. Often, design information uncertain, scatter and comes from various sources. Coordination should be viewed as a process to handle the uncertainty and to synchronize the flow of information, which is essential for enhancing the project performance [12]. Coordination process tries to increase collaboration between the stakeholders, managers and labourers, in order to know the impact of their work. Thus, the assignments should be sound regarding their prerequisites. This means, the task should not start until all the items required for its completion are available. However, in this procedure contrasts to the conventional project management approach, where execution just consists of task authorization.

The framework in Figure 2 below comprises from three main levels: (i) the construction parties; (ii) the construction project life cycle; and (iii) a set of coordination development approaches aimed at supportive the actions through the project life cycle. The sub-actors of each party form the basis of the framework, since the success of coordination application straight depends on them. Top Management of each party was located at the top of the schematic because they lead the coordination efforts. With regard to coordination between the same party sub-actors, top management should establish the coordination vision and policy for them. However, the coordination of work and service that the party provides should be considered during the project life cycle. The dimensions associated with both of these aspects can be used as checklists to ensure the coordination process efficient application. The intermediate part of the framework displays the construction procedure and its phases, each of which may be reinforced by the use of dissimilar coordination development approaches and technology.

Figure 2: Coordination process framework in construction projects

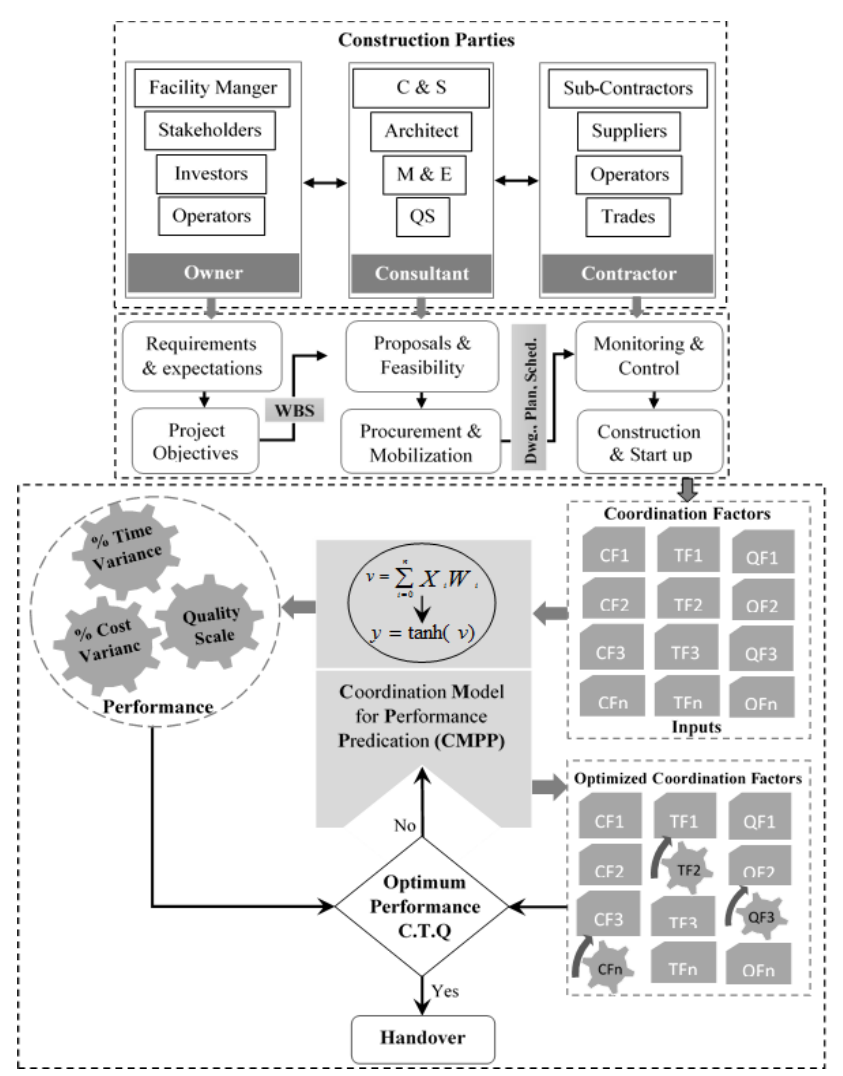

The proposed framework has included most of the construction projects restrictions found in association to coordination process. It considers coordination process from three different perspectives: owner, consultant and contractor, it include the whole project life cycle, and proposed both performance development approaches and factors to execute them. In addition, it has novel features, because the framework endorses the application of the coordination theory "a scarcely explored theory in the construction sector", inspires to harmonize the effort done by different parties, a generally neglected area within the construction industry. Therefore, the work supposed to be efficient from the first time and puts the voice of reduce the re-work, at the core of the project. Using the framework, a well empathetic and awareness of sustain relationships can be predictable. Companies can also expect improved communication between the main parties and their sub-actors from one side and different parties from the other side [5].

Coordination is an iterative process of gradually trust building, understanding and working relationships. The cooperation and coordination spectrum, conceptualized by Nan and Strimling [19], outlines the different degrees of coordination as in Table 2 . The coordination process has four overall levels of intensity process (communication, coexistence, coordinated action, or integrated action). To move toward the coordination it is important to understand 
the environment in which coordination will take place and the capacities and interests of the involved actors. It is essential to determine the degree of coordination necessary for the parties to develop a process to help in knowledge building and relationships necessary to meet these common objectives.

Table 2: Degrees of coordination level project management

\begin{tabular}{|c|c|c|c|}
\hline$\underset{\text { ion }}{\text { Communicat }}$ & Coexistence & $\begin{array}{l}\text { Coordinated } \\
\text { Action }\end{array}$ & $\begin{array}{c}\text { Integrated } \\
\text { Action }\end{array}$ \\
\hline $\begin{array}{l}\text { Information } \\
\text { conveyance } \\
\text { between } \\
\text { parties - } \\
\text { limited to } \\
\text { sharing. }\end{array}$ & $\begin{array}{l}\text { Cohabitation } \\
\text {, joint } \\
\text { context, and } \\
\text { capacity } \\
\text { analysis with } \\
\text { developed } \\
\text { partially. } \\
\text { More than } \\
\text { sharing. }\end{array}$ & $\begin{array}{l}\text { Joint design } \\
\text { and/or } \\
\text { implementati } \\
\text { on of specific } \\
\text { activities; } \\
\text { sustain active } \\
\text { partnership. } \\
\text { Consider the } \\
\text { others } \\
\text { capacities. }\end{array}$ & $\begin{array}{l}\text { Different } \\
\text { parties } \\
\text { working } \\
\text { together. } \\
\text { Collaboration } \\
\text { in decision- } \\
\text { making and } \\
\text { evaluation } \\
\text { mechanisms } \\
\text { for goals. }\end{array}$ \\
\hline
\end{tabular}

Once the mechanism of coordination process are understood and the roles that each party will play are clearly decided, it is necessary to establish the objectives of coordination process. Therefore, the objectives do not overlap or contradict, however, develop consolidated objectives, or integrated objectives $[6,19]$.

\section{Conclusions}

The construction industry is in its infancy of coordination process. One of the unique characteristic of construction industry is that unlike any other industry, there is a strong inter-firms coordination required across the entire project life cycle. Coordination is the process of getting all elements ready to enable crews to perform work in an effective and efficient manner from the first time. It is the guaranty for getting right information and material to right actor at time to improve productivity. Coordination is important for construction projects to manage the interfaces between the stakeholders. To enhance project performance, various coordination methods can be used, but coordination effectiveness needs to be assessed to find out if they are being used appropriately.

Despite the research efforts, there is no integrated framework for implementing coordination process has been proposed particularly for construction projects. The aim of this paper is to establish a framework for coordination process, to enhance workflow reliability during the project life cycle. The framework was developed based on the coordination theory and its application experience in different disciplines. After the systematic literature review, interviews were conducted with, five managers and engineers of to quantify their coordination quality, quantity, and effectiveness. The coordination quality, quantity, and effectiveness scores were analyzed to identify their internal relationships and their effects on project performance.

\section{References}

1. D. M. Gann and A. J. Salter, "Innovation in project-based, service-enhanced firms: the construction of complex products and systems," Research policy, vol. 29, pp. 955-972, 2000.

2. S. A. Assaf and S. Al-Hejji, "Causes of delay in large construction projects," International journal of project management, vol. 24, pp. 349-357, 2006.

3. A. Razak Bin Ibrahim, M. H. Roy, Z. Ahmed, and G. Imtiaz, "An investigation of the status of the Malaysian construction industry," Benchmarking: An International Journal, vol. 17, pp. 294-308, 2010.

4. M. Harvey, "Privatization, fragmentation and inflexible flexibilization in the UK construction industry," Building chaos: An international comparison of deregulation in the construction industry, pp. 188-209, 2003.

5. W. J. O'brien, "Construction supply-chain management: a vision for advanced coordination, costing, and control," in NSF Berkeley-Stanford Construction Research Workshop, Stanford, California, 1999.

6. X. Xue, Y. Wang, Q. Shen, and X. Yu, "Coordination mechanisms for construction supply chain management in the Internet environment," International Journal of project management, vol. 25, pp. 150-157, 2007.

7. A. Akintoye, G. McIntosh, and E. Fitzgerald, "A survey of supply chain collaboration and management in the UK construction industry," European Journal of Purchasing \& Supply Management, vol. 6, pp. 159-168, 2000.

8. X. Xue, X. Li, Q. Shen, and Y. Wang, "An agentbased framework for supply chain coordination in construction," Automation in construction, vol. 14, pp. 413-430, 2005.

9. A. Dubois and L.-E. Gadde, "The construction industry as a loosely coupled system: implications for productivity and innovation," Construction Management \& Economics, vol. 20, pp. 621-631, 2002.

10. D. D. d. Saram and S. M. Ahmed, "Construction coordination activities: What is important and what consumes time," Journal of Management in Engineering, vol. 17, pp. 202-213, 2001.

11. P. Love, G. D. Holt, L. Shen, H. Li, and Z. Irani, "Using systems dynamics to better understand change and rework in construction project management systems," International Journal of Project Management, vol. 20, pp. 425-436, 2002.

12. T. W. Malone and K. Crowston, "What is coordination theory and how can it help design cooperative work systems," in Proceedings of the 1990 ACM conference on Computer-supported cooperative work, 1990, pp. 357-370.

13. K. Crowston, "A coordination theory approach to organizational process design," Organization Science, vol. 8, pp. 157-175, 1997. 
14. A. S. Chang and F.-Y. Shen, "Coordination needs and supply of construction projects," Engineering Management Journal, vol. 21, pp. 44-57, 2009.

15. Y. Wang, "Coordination issues in Chinese large building projects," Journal of Management in Engineering, 2000.

16. T. Hegazy, E. Zaneldin, and D. Grierson, "Improving design coordination for building projects. I: Information model," Journal of Construction Engineering and Management, vol. 127, pp. 322-329, 2001.

17. L. Hossain, "Communications and coordination in construction projects," Construction Management and Economics, vol. 27, pp. 25-39, 2009.

18. A. Caballero, S. Ahmed, S. Azhar, and M. Barcala, "Development of an information model to enhance integration and coordination in the construction projects," NIST SPECIAL PUBLICATION SP, pp. 123-128, 2003.

19. S. A. Nan and A. Strimling, "Coordination in conflict prevention, conflict resolution and peacebuilding," International Negotiation, vol. 11, pp. 1-6, 2006. 